\title{
HUMANITARIAN AID DISTRIBUTION FRAMEWORK FOR NATURAL DISASTER MANAGEMENT
}

\author{
S. Mohd ${ }^{1}$, M. S. Fathi ${ }^{2,}$, A. N. Harun ${ }^{1}$ \\ ${ }^{1}$ Malaysia Japan International Institute of Technology (MJIIT), Universiti Teknologi Malaysia (UTM), 54100 Kuala Lumpur, \\ Malaysia - suzilamohd@gmail.com, aizulnahar.kl@utm.my \\ ${ }^{2}$ UTM Razak School of Engineering and Advanced Technology, Universiti Teknologi Malaysia (UTM), 54100 Kuala Lumpur, \\ Malaysia-syazli@utm.my
}

Commission VI, WG VI/4

KEY WORDS: Disaster Management, Humanitarian Aid Distribution Framework, Humanitarian Aid Distribution System

\begin{abstract}
:
Humanitarian aid distribution is associated with many activities, numerous disaster management stakeholders, enormous effort and different processes. For effective communication, humanitarian aid distribution activities require appropriate and up-to-date information to enhance collaboration, and improve integration. The purpose of this paper is to develop a humanitarian aid distribution framework for disaster management in Malaysia. The findings of this paper are based on a review of the humanitarian aid process and interviews with disaster management stakeholders. Findings reveal that, poor coordination and lack of good communication among disaster management stakeholders are the major issues within the humanitarian aid distribution process in developing countries. These issues could have adverse consequences for the objectives and success of the humanitarian aid distribution activities in disaster management. Therefore, to reduce these issues, a humanitarian aid distribution framework is proposed to support appropriate deliveries, improve the monitoring process, facilitate team coordination, improve government interagency collaboration and improve communication among disaster management stakeholders. The proposed humanitarian aid distribution framework sets out to overcome the food redundancy problem, the uneven distribution of food supply to disaster victims and food insecurity issues in developing countries. It is anticipated that this research will establish a systematic humanitarian aid distribution system by enhancing its process, improving its efficiency and maximising its effectiveness.
\end{abstract}

\section{INTRODUCTION}

\subsection{Humanitarian Aid}

Natural disasters have caused significant physical damage, loss of life or drastic change to the environment (Kwasinski et al., 2009). They could happen anytime, anywhere and are unavoidable (Baharin et al., 2009). According to Kryvasheyeu et al. (2015), natural disasters are costly in terms of property, political stability and lives lost. Climate change has caused several disasters such as hurricanes, floods and tornadoes which have become more common, intense and subsequently more costly (Kryvasheyeu et al., 2016; Mendelsohn et al., 2012). During a disaster, people will obviously respond by accommodating, protecting, retreating and also doing nothing (Takeuchi, 2002). Therefore, the role of humanitarian aid distribution activities in responding and helping the victims during a natural disaster has become an extensive activity to relieve the burdens on disaster victims.

With regard to disaster management, several stakeholders have been involved in managing humanitarian aid distribution. The stakeholders consist of government agencies, non-government organizations (NGOs), volunteers and the private sector (Careem et al., 2006; Ismail et al., 2014; O'Brien et al., 2006) and are responsible for managing humanitarian aid to disaster victims. Basically, the stakeholders will provide facilities and necessities to disaster victims and rescuers such as food, medical treatment and evacuation as well as other emergency assistance (Careem et al., 2006). Essentially, humanitarian aid distribution activities should be provided in accordance with three (3) main principles, which are humanity, neutrality and impartiality (Irrera, 2018). According to Irrera (2018), humanity is shown to the most vulnerable disaster victims, wherever they are. Second, neutrality here means that humanitarian aid should be distributed neutrally without engaging in hostilities or taking sides. Lastly, impartiality, as explained by Irrera (2018), is the distribution of humanitarian aid without discrimination.

With regard to providing humanitarian distribution activities according to the principles mentioned by Irrera (2018), there are five (5) main important factors that should be considered. These are highlighted by several authors identified through a literature reviews on humanitarian aid management. The factors are information (van der Laan et al., 2016; Yilmaz \& Kabak, 2016), communication (Madianou et al., 2015; Martin et al., 2016), collaboration (Martin et al., 2016; Nagurney et al., 2016), coordination (Martin et al., 2016; Richardson et al., 2016) and cooperation (Joshi \& Nishimura, 2016; Martin et al., 2016). These are the key success factors for disaster management stakeholders in managing the humanitarian aid distribution process efficiently and effectively. Details on each factor are explained in the next sub-section. 


\subsection{Factors to Manage Humanitarian Aid Distribution}

The five (5) key success factors for disaster management stakeholders to manage the humanitarian aid distribution process efficiently and effectively are discussed as follows.

1.2.1 Information: Accurate, real-time information regarding a disaster is needed to carry out the humanitarian aid process smoothly (Yilmaz \& Kabak, 2016). Moreover, the correct information on a disaster could increase the number of donations from NGOs and the private sector in order to mitigate the loss from the disaster (Sankaranarayanan et al., 2018).

1.2.2 Communication: Communication, also known as 'the act of transmitting' is explained by Martin et al. (2016) as a medium to distribute a message or information in an organisation or between two (2) different organisations. During the disaster response, communications have become more sophisticated due to new developments in information and communications technology (ICT) for disaster management. Celik and Corbacioglu (2010) discovered that well-functioning ICT in disaster management could positively affect the disaster response and facilitate coordination among disaster management stakeholders.

1.2.3 Cooperation: Cooperation refers to informal shortterm relationships between voluntary groups and organisations (Martin et al., 2016). It has also been characterised as organisations with low levels of strength and risk of working together. The main reason to cooperate with other organisations during a disaster occurrence or emergency is to balance the disaster management stakeholders' strengths and weaknesses in managing the humanitarian aid distribution process. Moreover, it is important in order to avoid programme duplication in providing humanitarian aid (Martin et al., 2016).

1.2.4 Coordination: According to Martin et al. (2016), coordination is a process of organising disaster management stakeholders so that they can manage the humanitarian aid distribution process together properly and effectively based on their common objectives. An effective inter-organisational coordination is dependent on the level of information-sharing between the disaster management stakeholders. For this reason, coordination is also important to monitor or facilitate the logistic operations, particularly commodity delivery and evacuation centres (Al Theeb \& Murray, 2016).

1.2.5 Collaboration: Collaboration in disaster management is commonly illustrated as a long-lasting relationship between disaster management stakeholders (Martin et al., 2016). Collaboration in disaster management is important in order to increase the quality of humanitarian aid management execution because it is impossible for any single organisation to manage the disaster situation alone (Martin et al., 2016). Moreover, the collaboration between government agencies and NGOs should form part of their preparation before a disaster (Nagurney et al., 2016).

\subsection{Disaster Management Stakeholders}

Disaster management stakeholders form a group of people, which provide assistance or help during or after a disaster. The disaster management stakeholders may be from many agencies. According to Asproth et al. (2010) disaster management stakeholders may be governmental agencies, non-government organisations (NGOs) or spontaneous helpers comprised of individual citizens or temporary groups of citizens. Each of the stakeholders will vary widely in agility, competence, resources and endurance. Figure 1 shows the disaster management stakeholders, which consists of government agencies, NGOs, volunteers and the private sector.

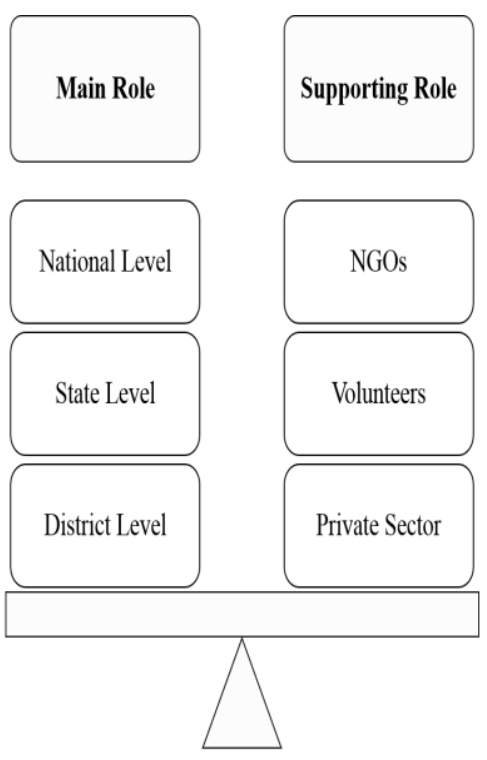

Disaster Management Stakeholders

Figure 1. Disaster Management Stakeholders

For instance, in Malaysia, the government agencies involved in disaster management are divided into three (3) levels which are, Level I: District Disaster Management and Relief Committee, Level II: State Disaster Management and Relief Committee and Level III: National Disaster Management and Relief Committee (Center for Excellence in Disaster Management and Humanitarian Assistance, 2016; National Security Council, 1997). Each disaster management committee at district, state and national level has to carry out its own roles and responsibilities during a disaster occurrence based on current legislation for disaster management in Malaysia, which is currently Directive No.20.

Meanwhile, NGOs are any non-profit-organization or voluntary citizen group that is independent from states and international government organizations. The role of NGOs in disaster management is to perform a variety of service and humanitarian functions. NGOs are also known as 'implementing partners' for government programmes that accommodate and protect the disaster victims (Abiew, 2012). Apart from that, the role of the private sector also lightens that of the government agencies in meeting the disaster victims' needs. Basically, the private sector provides the volunteers involved in managing disaster aid distribution, which for many industries is a form of their engagement in Corporate Social Responsibility (CSR) partnerships (de Oliveira et al., 2016).

\section{RESEARCH METHODOLOGY}

\subsection{Data and Methods}

This paper is based on output from primary and secondary sources to understand the overall concept and process in managing humanitarian aid distribution during and postdisaster. Firstly, primary data was collected through multiple case studies of disaster prone areas in three (3) states of 
Malaysia, which are Pahang, Terengganu and Kelantan as illustrated in Figure 2. Semi-structured interviews have been conducted with government officials from national, state and district levels as well as selected NGOs that engage in managing the humanitarian aid distribution process in Malaysia. The interviews were conducted in face-to-face settings. Findings from the interviews revealed that all the participants have more than 5 years' experience in managing the humanitarian aid distribution process in the disaster prone areas of Malaysia.

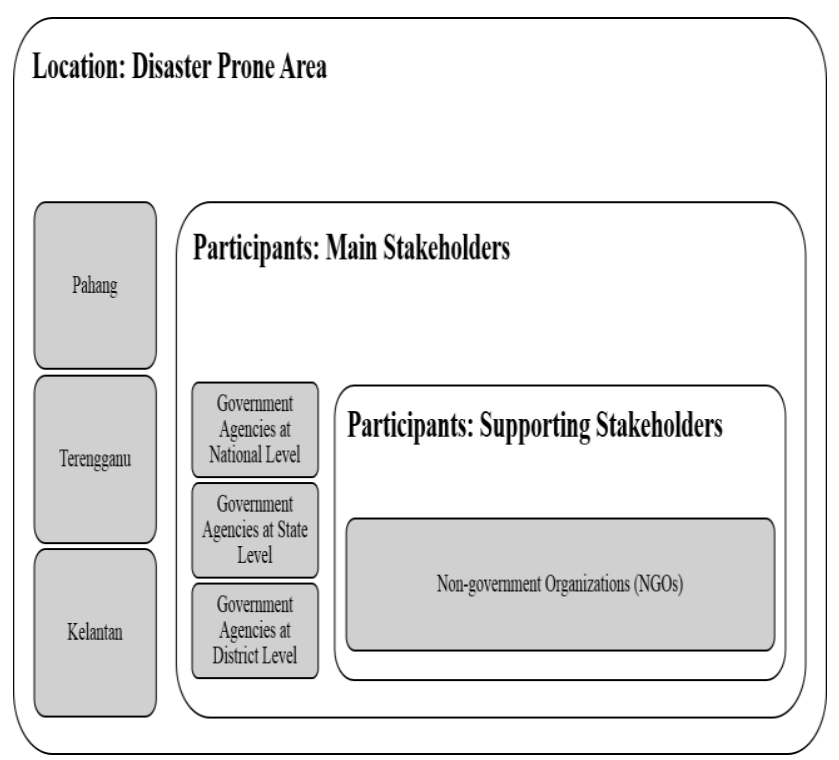

Figure 2: Multiple case studies conducted in disaster prone areas of Malaysia

Secondly, secondary sources were accessed through a literature review in order to gain information related to humanitarian aid distribution such as its concept, process, success factors and disaster management teams. Various sources were reviewed, such as books, journal articles, international conference papers, government reports and material available on the internet.

Finally, all data and information obtained from primary and secondary sources were analysed using content analysis techniques. The content analysis viewed data representation through text, images and expressions. The following section discusses the result and findings from the interviews.

\section{RESULT AND FINDINGS}

There have been substantial efforts in managing the humanitarian aid distribution process during natural disasters but the absence of a humanitarian aid distribution process framework for natural disaster management has limited their effectiveness. The humanitarian aid distribution process framework for natural disaster management was developed based on findings from both primary and secondary sources and is presented in Figure 3.

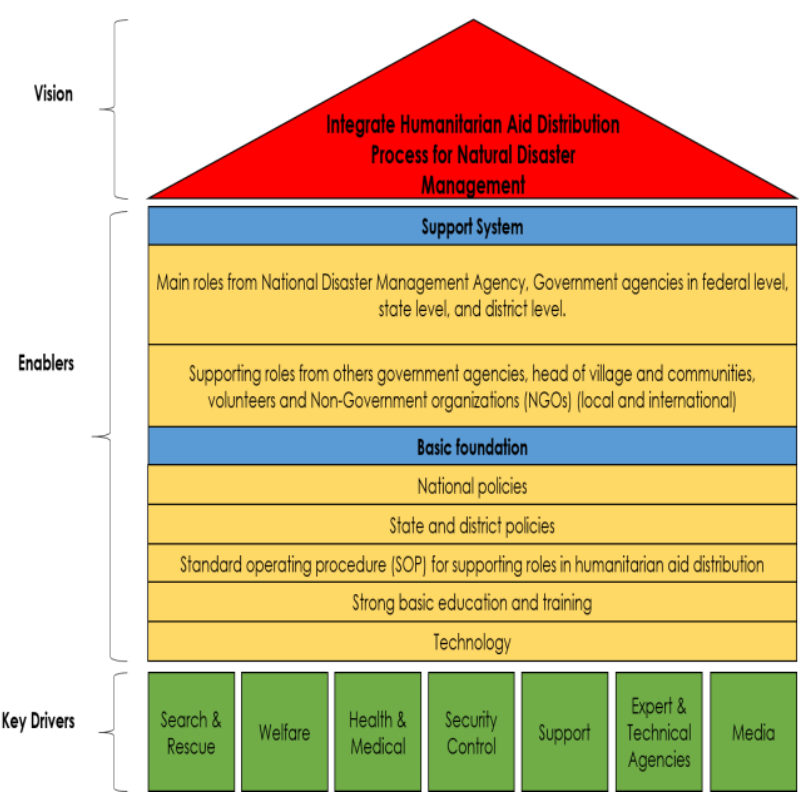

Figure 3: Humanitarian Aid Distribution Framework for Natural Disaster Management

\subsection{Vision}

The main vision of the framework is to integrate the humanitarian aid distribution process for natural disaster management. The proposed vision is intended to enhance the humanitarian aid distribution process. All the participants agreed that all disaster management stakeholders involved in the humanitarian aid distribution process should have at least one standard vision. All participants in this research have explained and highlighted that there is a need to integrate the humanitarian aid distribution process during a disaster. The integration between disaster management stakeholders could improve the humanitarian aid distribution process during and post-disaster to become more effective and efficient.

\subsection{Key Drivers}

The term 'key drivers' in the framework shown in Figure 3 is defined as the leading factors affecting performance for a humanitarian aid distribution process. It could also be known as service themes in managing humanitarian aid distribution during disaster and post-disaster as mention in the National Security Council (1997) and as explained by all Government Officer (GO) participants in the interviews in this research. Detailed findings from all participants on each service theme are presented as follows: 
3.2.1 Search and Rescue: All participants agreed that the main activity in the humanitarian aid distribution process is search and rescue. This is the first team that responds to the disaster victim during a disaster. This is in line with Dugdale et al. (2012), who stated that search and rescue is the first service theme performed during a disaster. The search and rescue team have to find and evacuate the disaster victims to the evacuation center. All participants also agreed that the search and rescue activity during a disaster should be improved in order to avoid difficulties in adequately managing crises. The government agencies involved in the search and rescue service theme are the Special Malaysia Disaster Assistance and Rescue Team (SMART), the Fire and Rescue Department, the Royal Malaysia Police, Malaysian Armed Forces, the Civil Defence Department, the Ministry of Health and other agencies.

3.2.2 Welfare: The main role of welfare in humanitarian aid during and post-disaster according to all participants is to place the disaster victims in a safe place, preparing food for disaster victims and the duty officers, providing and managing the place(s) of evacuation, as well as providing first aid and counselling services to the disaster victims. The government agencies involved in the welfare service theme are the Department of Social Welfare, the Ministry of Health, the Malaysia Red Crescent, the Civil Defence Department, the People's Volunteer Corps of Malaysia (RELA), the Ministry of Tourism and other related agencies.

3.2.3 Health and Medical: According to all the participants, the health and medical role in humanitarian aid during a disaster is to manage emergency treatment, forensic services and public health. All the disaster victims should receive medical treatment during a disaster at the evacuation centre. The government agencies involved in the health and medical service theme as explained by all GO participants are the Ministry of Health, Malaysian Armed Forces, the Malaysia Red Crescent, the Civil Defence Department and other agencies.

3.2.4 Security Control: The role of security control during a disaster occurrence as explained by all participants is to provide control at the scene of an incident, conduct an investigation and facilitate communication among the disaster victims. All GO participants mentioned that the Royal Malaysian Police and the People's Volunteer Corps of Malaysia are the agencies involved in security control service themes.

3.2.5 Support: Support is one of the service themes required in managing the humanitarian aid distribution process. All respondents explained that the role of support as a service theme in humanitarian aid is to help in terms of logistics, relationships and other assistance to smooth out the operation movement control to overcome the disaster. All GO participants explained that government agencies in Malaysia involved in this service theme consist of district officers, municipal or town councils, Tenaga Nasional Berhad (TNB), Telekom Malaysia Berhad, the Malaysian Armed Forces, the Public Works Department and other related agencies.
3.2.6 Expert and Technical Agencies: This service is needed in order to prepare reports on the incidents and to advise the search and rescue team on disaster response and assistance. The expert and technical agencies are needed in order to investigate the disaster situation. Moreover, their opinion and investigation report could help the government agencies to make improvements in mitigating the effects of a disaster. All GO participants mentioned that the expert and technical agencies involved in this service theme are the experts on subject matter, which depends on the type of disaster that occurs.

3.2.7 Media: The role of the media is important during a disaster to ensure press, electronic and media coverage, as well as media control for distributing information on the disaster to civilians. All participants explained that this is important in order to inform the civilians about the current situation of disaster victims and the disaster area to which access is restricted during the disaster. The agencies involved in the media service theme are the information department and the broadcasting department.

\subsection{Enablers}

The term 'enabler' in the framework refers to a person or organization or thing that makes something possible. All the participants have mentioned and highlighted several important elements in managing the humanitarian aid distribution process. The elements have been categorized into two (2) types of enablers, which are the support system and the basic foundation. Detailed findings from all participants on both enablers are presented as follows:

3.3.1 Support System: The support system in managing the humanitarian aid distribution process is divided into two (2) categories: the main stakeholder and the supporting stakeholders, also known as disaster management stakeholders. The main roles mentioned by all participants are adopted by the focal agency in a country at the national, state and district levels. The roles, responsibilities and the government agencies involved in managing humanitarian aid distribution during a disaster have been discussed and mentioned in each service theme or the key drivers in sub-section 3.2.

Meanwhile, the supporting stakeholder is geared towards the role of other government agencies, NGOs, volunteers and the private sector. The roles and responsibilities of disaster management stakeholders in humanitarian aid distribution are important in order to accommodate and help the disaster victims. However, based on explanations by all the participants, the roles and responsibilities of supporting stakeholders during a disaster have been mentioned in current legislation (Directive No.20) but this just defines other agencies in each type of service theme or the key drivers in managing the humanitarian aid distribution process. All the NGO participants explained that, even though their existence is highlighted in Directive No. 20 , their roles and responsibilities as a supporting stakeholder in providing humanitarian aid are not clearly defined under the current loose legislation. 
3.3.2 Basic Foundation: There are four (4) basic foundations required in managing the humanitarian aid distribution process. All the information was gained from the interviews with all the participants. The basic foundation in managing humanitarian aid explained and highlighted by all participants are (1) National, State and District policy, (2) the Standard Operating Procedure (SOP) of the humanitarian aid distribution process, (3) Training and Education and (4) Technology.

First, National, State and District Policy. There is a need to have a clear policy at national, state and district levels for managing humanitarian aid in a disaster. The policy acts as an outline of a comprehensive disaster management mechanism covering pre-disaster, during a disaster and post-disaster levels. Each agency involved in disaster management is responsible for implementing their respective roles in line with the policy. Specifically, disaster management should also be integrated with all the agencies to ensure the actions taken at each level become more efficient and effective. Moreover, the use of the policy could prevent any wastage, confusion, conflict and discrepancies or duplication of roles in addressing the disaster. Each of the government agencies involved in managing humanitarian aid at each level (national, state an district) needs to have a detailed policy according to their roles and responsibilities at each level.

Second, Standard Operating Procedure (SOP) in managing humanitarian aid. It is clearly explained by all GO participants that each government agency involved in humanitarian aid has their own SOP that is based on the National Policy and their department. All the operations conducted by government agencies during a disaster should be based on the SOP. However, according to all NGO participants, there is no standard SOP for them as the supporting stakeholders in order to become involved in the humanitarian aid distribution process during and post-disaster. All the NGOs mentioned that each of their organizations has its own SOP in managing humanitarian aid distribution locally and internationally, but they did not know how far their SOP is matched with the government agencies' SOP in managing the humanitarian aid distribution process. Apart from that, due to the absence of an SOP for supporting stakeholders in managing the humanitarian aid distribution process they have to manage the humanitarian aid distribution process based on their own SOP

However, all NGO participants mentioned that the national disaster management agency of Malaysia should provide a standard SOP or standard procedure or process for supporting stakeholders eager to become involved in the humanitarian aid process. This is important in order to avoid any problems during a disaster occurrence. With the SOP, the supporting stakeholders will understand their limits in managing the humanitarian aid distribution process during a disaster. Therefore, all the participants agreed that there is a need to develop or create a standard SOP that can be used by supporting stakeholders in managing the humanitarian aid distribution process. In future, the SOP could be their guidance during a disaster and post-disaster in managing and monitoring the humanitarian aid distribution process.

Next, training and education. All the GO participants explained and agreed that all disaster management stakeholders, either government agencies or supporting stakeholders, should be trained properly before participating in any humanitarian aid distribution activities. Both training and education are important in order to increase awareness and knowledge regarding roles, responsibilities, do's and don'ts when managing humanitarian aid, especially in the search and rescue service theme. All NGO participants explained that all the volunteers involved in their organization will be trained until the volunteers are able and qualified to join the humanitarian aid distribution activities during or post-disaster. All participants explained that training and education are needed for each disaster management stakeholder, so they will understand their own roles and responsibilities when managing the humanitarian aid distribution process in order to reduce unnecessary risk.

Lastly, technology. In the fourth industrial revolution, people used information and communication technology (ICT) as a tool to build and extend the impact of digitization in their daily activities. The used of ICT in disaster management has been widely increasing (Bernardo et al., 2015; Carley et al., 2016) as a tool for enhancing communication and collaboration among disaster management stakeholders. These beliefs are in line with all the participants in this research who agreed that there is a need to use the latest or most suitable technology that could enhance the humanitarian aid distribution process. The use of technology explained by all the participants could help the disaster management stakeholder to share and at the same time control the disaster information between them. Even though, sometimes the technology could be harmful and cause some problems, all the participants strongly believe that the use of technology could reduce their workload when managing humanitarian aid distribution. Most importantly, all the participants agreed that the use of technology could improve communication, collaboration and coordination between disaster management stakeholders in delivering disaster information. They believe that a proper technology used in humanitarian aid could eliminate several problems such as fraudulent reports (Gao et al., 2011; Ha, 2016) or redundancy of information (Gao et al., 2011) on a disaster that affects the humanitarian aid distribution process. Problems include food redundancy, the uneven distribution of food supply to disaster victims, and food insecurity issues (Hussain \& Ismail, 2011).

\section{DISCUSSION}

All disaster management stakeholders collaborate and cooperate together to provide compassionate aid to the disaster victims in the form of shelter, food, medical attention and basic needs. However, limited knowledge regarding humanitarian aid management has lead to several problems such as food redundancy, the uneven distribution of food supplies to disaster victims, food insecurity issues and the over-concentration of NGOs and volunteers in particular affected areas. The problems show that there are weaknesses in managing the humanitarian aid distribution process among the disaster management stakeholders. Therefore, the proposed framework aims to increase knowledge about humanitarian aid management and strengthen the process.

Moreover, in this paper we have analysed the main criteria needed in managing the humanitarian aid distribution process from the general view of disaster management stakeholders' decision-making to the specific characteristics of a particular context. We have presented a humanitarian aid management framework as a solution to address humanitarian aid management problems. All the elements in the framework are certainly needed by the disaster management stakeholders to deal with different situations. Among the main criteria in the framework, we can identify those related with each disaster 
management stakeholder, together with their specificities. The key drivers mentioned in the framework refer to the main humanitarian aid distribution activities during a disaster. The key drivers are the basic knowledge of the disaster management stakeholder about helping the disaster victims. Strong collaboration and cooperation is needed in executing all the service themes stated as key drivers because each service theme involves different disaster management stakeholders.

Therefore, the role of the support system and basic foundation are important in order to ensure that all the key drivers are being well implemented during a disaster by all the disaster management stakeholders. All the information stated as enablers in the frameworks highlighted a need in order to implement the key enablers. The information could increase the knowledge of government agencies as the focal agency in disaster management to improve and produce all the basic foundations required by all the disaster management stakeholders. The basic foundations stated in the framework will enable all the disaster management stakeholders to become clearer about their roles and responsibilities in managing the humanitarian aid distribution process.

\section{CONCLUSION}

The humanitarian aid management framework proposed in this paper will hopefully enhance its process, reduce problems, improve its efficiency and maximise its effectiveness. The framework could become a guideline for the disaster management stakeholders in managing the humanitarian aid distribution process. It will also increase the disaster management stakeholders' knowledge so that they can identify the most important criteria or elements needed in managing the humanitarian aid distribution process. All the information highlighted in the framework could integrate the humanitarian aid distribution process so it can respond to all types of disaster.

Consequently, in order to improve the integration of the humanitarian aid distribution process for natural disaster management among the disaster management stakeholders, further research is being conducted in developing an integrated humanitarian aid distribution system. The system will become one of the outputs from the technology basic foundation section of the framework.

\section{ACKNOWLEDGEMENTS}

This work was financially supported by a Seed Grant of "Advanced Institute on Knowledge-Based Actions for Disaster Risk Reduction (AI-KBA)" from The International Council for Science - Regional Office for Asia and The Pacific (ICSUROAP) and Universiti Teknologi Malaysia Fundamental Research Grant Scheme (UTM-FRGS Grant No. 4F951) under the Ministry of Education, Malaysia.

\section{REFERENCES}

Abiew, F. K. (2012). Humanitarian Action under Fire: Reflections on the Role of NGOs in Conflict and Post-Conflict Situations. International Peacekeeping, 19(2), 203-216. doi:10.1080/13533312.2012.665698

Al Theeb, N. \& Murray, C. (2016). Vehicle routing and resource distribution in postdisaster humanitarian relief operations. International Transactions in Operational Research.
Asproth, V., Amcoff Nyström, C. \& Dubois, D. M. (2010). Preparing for Emergency Situations. Paper presented at the AIP Conference Proceedings.

Baharin, S. S. K., Shibghatullah, A. S. \& Othman, Z. (2009). Disaster management in Malaysia: An application framework of integrated routing application for emergency response management system. Paper presented at the Soft Computing and Pattern Recognition, 2009. SOCPAR'09. International Conference of.

Bernardo, J. B., Huavas, K. M., Ociones, G. O., Pantuan, R. A. \& Vasallo, J. M. P. (2015). Crowdalert: An Android Application for Increasing the Awareness and Response Initiatives of the Citizens through Crowdsourcing. 3rd International Conference on Artificial Intelligence and Computer Science (AICS2015).

Careem, M., De Silva, C., De Silva, R., Raschid, L. \& Weerawarana, S. (2006). Sahana: Overview of a disaster management system. Paper presented at the Information and Automation, 2006. ICIA 2006. International Conference on.

Carley, K. M., Malik, M., Landwehr, P. M., Pfeffer, J. \& Kowalchuck, M. (2016). Crowd sourcing disaster management: The complex nature of Twitter usage in Padang Indonesia. Safety Science. doi:http://dx.doi.org/10.1016/j.ssci.2016.04.002

Center for Excellence in Disaster Management and Humanitarian Assistance, C.-D. (2016). Malaysia Disaster Management Reference Handbook. Malaysia.

de Oliveira, P. M., Fontainha, T. C., \& Leiras, A. (2016). The Role of Private Stakeholders in Disaster and Humanitarian Operations. JOSCM: Journal of Operations and Supply Chain Management, 9(1), 77.

Dugdale, J., Van de Walle, B. \& Koeppinghoff, C. (2012). Social media and SMS in the Haiti earthquake. Paper presented at the Proceedings of the 21st international conference on world wide web.

Gao, H., Barbier, G., Goolsby, R. \& Zeng, D. (2011). Harnessing the crowdsourcing power of social media for disaster relief. Retrieved from Arizona State Univ Tempe.:

Ha, K.-M. (2016). Disasters can happen to anybody: The case of Korea. Environmental Impact Assessment Review, 57 , doi:http://dx.doi.org/10.1016/j.eiar.2015.11.002

Hussain, T. P. R. S. \& Ismail, H. (2011). Land use changes analysis for Kelantan Basin using spatial matrix technique "Patch Analyst" in relation to flood disaster. Journal of Techno Social, 3(1).

Irrera, D. (2018). The EU Humanitarian Aid Policy and NGOs: A Theoretical Overview EU Emergency Response Policies and NGOs (pp. 27-44): Springer.

Ismail, D., Majid, T. A., Roosli, R. \& Samah, N. A. (2014). Project Management Success for Post-disaster Reconstruction Projects: International NGOs Perspectives. Procedia Economics and Finance, 18, 120-127. doi:http://dx.doi.org/10.1016/S22125671(14)00921-6

Joshi, A. \& Nishimura, M. (2016). Impact of disaster relief policies on the cooperation of residents in a postdisaster housing relocation program: A case study of the 2004 Indian Ocean Tsunami. International Journal of Disaster Risk Reduction, 19, 258-264. 
Kryvasheyeu, Y., Chen, H., Obradovich, N., Moro, E., Van Hentenryck, P., Fowler, J. \& Cebrian, M. (2015). Nowcasting disaster damage. arXiv preprint arXiv:1504.06827.

Kryvasheyeu, Y., Chen, H., Obradovich, N., Moro, E., Van Hentenryck, P., Fowler, J., \& Cebrian, M. (2016). Rapid assessment of disaster damage using social media activity. Science Advances, 2(3). doi:10.1126/sciadv.1500779

Kwasinski, A., Weaver, W. W., Chapman, P. L. \& Krein, P. T. (2009). Telecommunications power plant damage assessment for Hurricane Katrina-site survey and follow-up results. Systems Journal, IEEE, 3(3), 277287.

Madianou, M., Longboan, L. \& Ong, J. C. (2015). Finding a Voice Through Humanitarian Technologies? Communication Technologies and Participation in Disaster Recovery. International Journal of Communication, 9, 19.

Martin, E., Nolte, I. \& Vitolo, E. (2016). The Four Cs of disaster partnering: communication, cooperation, coordination and collaboration. Disasters.

Mendelsohn, R., Emanuel, K., Chonabayashi, S. \& Bakkensen, L. (2012). The impact of climate change on global tropical cyclone damage. Nature Climate Change, 2(3), 205.

Nagurney, A., Flores, E. A. \& Soylu, C. (2016). A Generalized Nash Equilibrium network model for post-disaster humanitarian relief. Transportation Research Part E: Logistics and Transportation Review, 95, 1-18.

National Security Council, N. (1997). Directive No.20. Malaysia: Majlis Keselamatan Negara.

O'Brien, G., O'Keefe, P., Rose, J. \& Wisner, B. (2006). Climate change and disaster management. Disasters, 30(1), 64-80.

Richardson, D. A., Leeuw, S. \& Dullaert, W. (2016). Factors affecting global inventory prepositioning locations in humanitarian operations - a delphi study. Journal of Business Logistics, 37(1), 59-74.

Sankaranarayanan, K., Castañeda, J. A. \& Villa, S. (2018). Future Research in Humanitarian Operations: A Behavioral Operations Perspective The Palgrave Handbook of Humanitarian Logistics and Supply Chain Management (pp. 71-117): Springer.

Takeuchi, K. (2002). Flood management in Japan-from rivers to basins. Water International, 27(1), 20-26.

van der Laan, E., van Dalen, J., Rohrmoser, M. \& Simpson, R. (2016). Demand forecasting and order planning for humanitarian logistics: An empirical assessment. Journal of Operations Management, 45, 114-122.

Yilmaz, H. \& Kabak, Ö. (2016). A Multiple Objective Mathematical Program to Determine Locations of Disaster Response Distribution Centers. IFACPapersOnLine, 49(12), 520-525. 